University of Nebraska - Lincoln

DigitalCommons@University of Nebraska - Lincoln

P. F. (Paul Frazer) Williams Publications

Electrical \& Computer Engineering, Department

February 1996

\title{
High-Temporal-Resolution, High-Sensitivity Imaging of Streamers in a Long Atmospheric Pressure Gap
}

\author{
W. J. Yi \\ University of Nebraska - Lincoln \\ B. J. Hankla \\ University of Nebraska - Lincoln \\ P. F. Williams \\ University of Nebraska - Lincoln, pfw@moi.unl.edu
}

Follow this and additional works at: https://digitalcommons.unl.edu/elecengwilliams

Part of the Electrical and Computer Engineering Commons

Yi, W. J.; Hankla, B. J.; and Williams, P. F., "High-Temporal-Resolution, High-Sensitivity Imaging of Streamers in a Long Atmospheric Pressure Gap" (1996). P. F. (Paul Frazer) Williams Publications. 15. https://digitalcommons.unl.edu/elecengwilliams/15

This Article is brought to you for free and open access by the Electrical \& Computer Engineering, Department of at DigitalCommons@University of Nebraska - Lincoln. It has been accepted for inclusion in P. F. (Paul Frazer) Williams Publications by an authorized administrator of DigitalCommons@University of Nebraska - Lincoln. 


\section{High-Temporal-Resolution, High-Sensitivity Imaging of Streamers in a Long Atmospheric Pressure Gap}

W. J. Yi, B. J. Hankla, and P. F. Williams

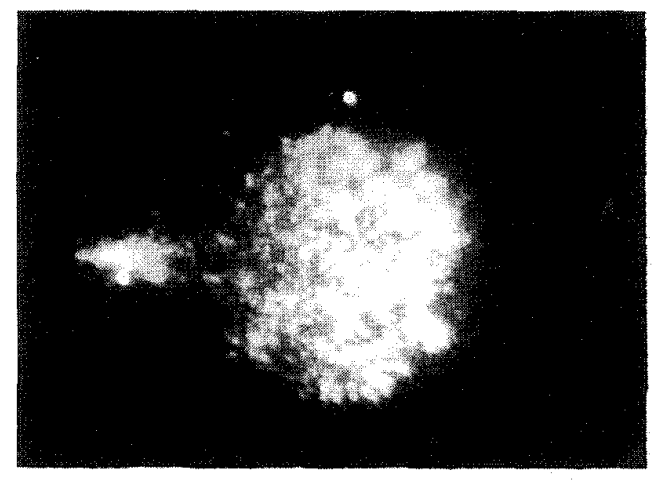

(a)

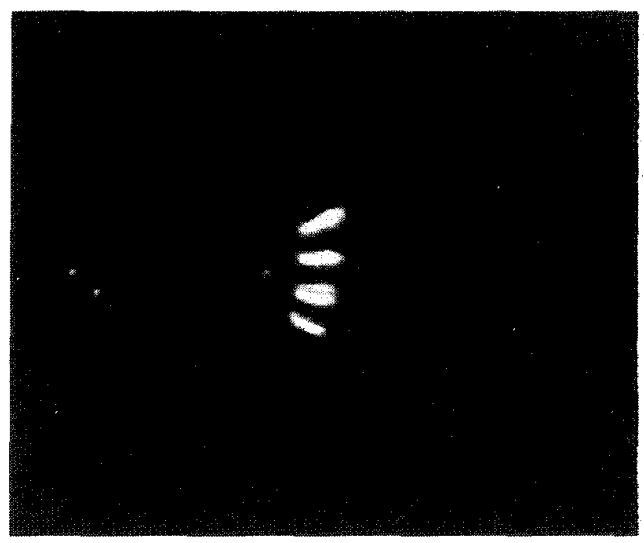

(c)

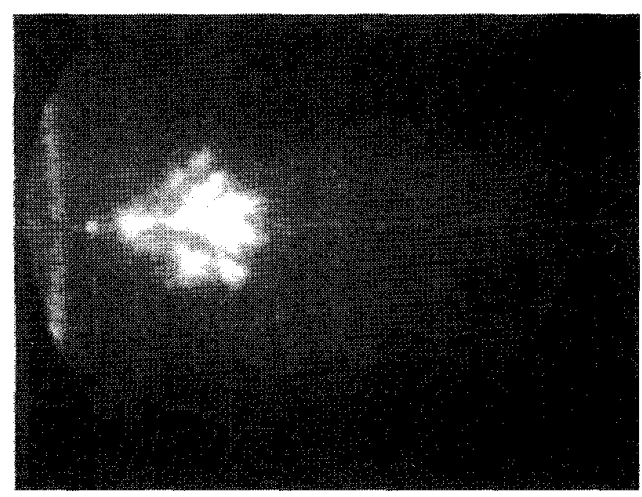

(b)

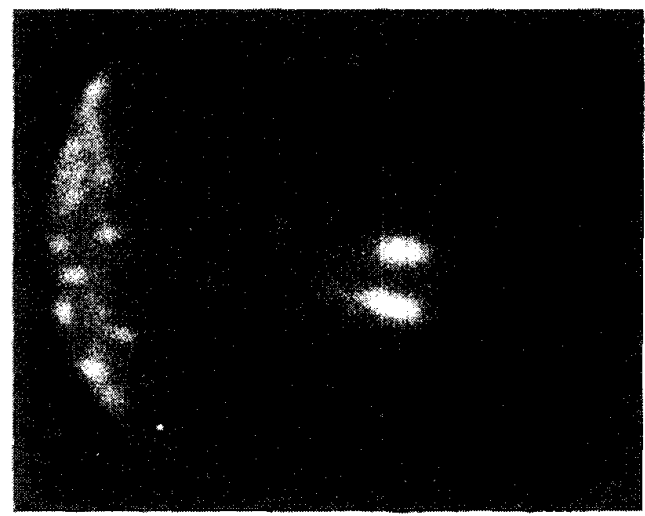

(d)

Fig. 1. Figure showing streamers in pure $\mathrm{N}_{2}$, (a) and (b), and mixtures containing $15 \%$, (c) and $1 \%$, (d), $\mathrm{O}_{2}$. Streamers in (a) and (c) are propagating toward the cathode, those in (b) and (d) toward the anode. In all cases, the initiating point is at the left of the photo. The total horizontal distance shown varies a little between photos and is about $16 \mathrm{~cm}$. The features at the far left in (b) and (d) are due to streamers initiated at the edge of the charged electrode.

Abstract-We present time-resolved shutter photographs of streamers in a $13-\mathrm{cm}$ gas-filled atmospheric pressure gap. The photographs show that in pure $\mathrm{N}_{2}$, the streamers split readily in two. In mixtures containing $\mathrm{O}_{2}$, on the other hand, this bifurcation is substantially reduced.

$\mathbf{R}$ AETHER [1], [2], Loeb [3], [4], and Meek [5] independently proposed similar mechanisms to explain the breakdown of relatively long gas-filled atmospheric pressure gaps. These mechanisms are based on the formation and

Manuscript received July 17, 1995.

The authors are with the Department of Electrical Engineering, University of Nebraska-Lincoln, Lincoln, NE 68588-0511 USA.

Publisher Item Identifier S 0093-3813(96)02242-4. propagation of phenomena which have come to be called streamers. Since that time, streamers have attracted sporadic attention in the literature, on both empirical and theoretical planes. We have obtained a large volume of time-resolved photographs of streamers propagating in a $13-\mathrm{cm} \mathrm{N}_{2}$-filled gap. These data provide new information about streamer formation and propagation. In this paper, we limit ourselves to the stability of streamers to bifurcation and the effect of gas composition on this stability.

The experimental setup consisted of a $0.7-\mathrm{m}$ diameter 1$\mathrm{m}$ long cylindrical tank containing two near-constant-field electrodes separated by about $13 \mathrm{~cm}$. This cylinder can be evacuated and then backfilled to any pressure up to about 2 atm. A short pointed tip extended about $1 \mathrm{~cm}$ outward into the 
gap from the charged electrode to seed streamer formation. Voltage pulses with 40-ns risetime and magnitude up to 150 $\mathrm{kV}$ were applied to the gap.

Both shutter and streak photography were used to observe the formation and propagation of streamers in the gap. In this paper, we present only shutter photographs. The shutter camera was locally constructed and based on an ITT F4144 gated microchannel plate intensifier. The camera is capable of nearsingle-photon sensitivity, and provides time resolution down to about $5 \mathrm{~ns}$.

Fig. 1(a) shows a typical shutter photograph of cathodedirected streamers obtained with a voltage pulse of $120 \mathrm{kV}$ in pure $\mathrm{N}_{2}$ at 760 torr. From the photo, it appears that one or a few streamers were launched from the sharp tip, and that these matriarch streamers then split into many generations of daughter streamers, in an expanding roughly spherical front. Fig. 1(b) shows a typical shutter photograph of anode-directed streamers obtained in pure $\mathrm{N}_{2}$ at 760 torr and $150 \mathrm{kV}$. The multiple branching seen with cathode-directed streamers is evident in this photo, but the individual streamers seem a bit thinner. This behavior is opposite to what one might expect, considering the direction of the electric field near the streamer tip. For a cathode-directed streamer, the field pulls electrons inwards towards the tip, whereas for an anodedirected streamer, the field pushes electrons outward.

The strong tendency of streamers of both polarity to split into many daughter streamers was commonly observed with a pure $\mathrm{N}_{2}$ fill. The addition of a small amount of $\mathrm{O}_{2}$ dramatically changes this tendency. Fig. 1(c) shows a photograph of cathode-directed streamers obtained in an 85/15 $\mathrm{N}_{2} / \mathrm{O}_{2}$ mixture. The pressure was 760 torr, and the voltage $110 \mathrm{kV}$. Fig. 1(d) shows a photo of anode-directed streamers obtained under similar conditions. The mixture was $99 / 1 \quad \mathrm{~N}_{2} / \mathrm{O}_{2}$, the pressure 760 torr, and the voltage $150 \mathrm{kV}$. The difference in appearance between streamers in pure and $\mathrm{O}_{2}$-containing mixtures is striking. In the mixtures, only a few well-defined streamers are formed, and they propagate across the gap with little splitting, whereas in pure $\mathrm{N}_{2}$, the streamers are continuously splitting in two.

It is not clear what the reason is for the difference in streamer behavior. One possibility is that $\mathrm{O}_{2}$ is an attacher of low-energy electrons, but $\mathrm{N}_{2}$ is not. If bifurcation requires an initial electron ahead of the streamer in the right place, then this difference might be responsible for the differing streamer behavior. We have a limited volume of data on streamers in $\mathrm{N}_{2} / \mathrm{SF}_{6}$ mixtures which is consistent with this hypothesis. $\mathrm{SF}_{6}$ is a strong electron attacher, and the appearance of streamers in these mixtures is similar to that in $\mathrm{O}_{2}$-containing mixtures.

We believe, however, that a more likely explanation is the difference in photoionization characteristics. Penney and Hummert [8] have published data showing the photoionization efficiency of pure $\mathrm{N}_{2}, \mathrm{O}_{2}$, and air. For both pure $\mathrm{O}_{2}$ and air, the photoionization efficiency falls off more slowly with distance than it does in $\mathrm{N}_{2}$. Preliminary numerical calculations suggest that bifurcation in pure $\mathrm{N}_{2}$ occurs because the streamer profile becomes increasingly flat and square-cornered. The peak field then moves off the streamer axis, and the streamer veers away from the initial propagation direction. The increased photoionization efficiency in $\mathrm{O}_{2}$-containing mixtures would be expected to reduce the peak field required to produce a propagating streamer, and might reduce the squaring-off effect observed in calculations for pure $\mathrm{N}_{2}$.

\section{REFERENCES}

[1] H. Raether, "Die Entwicklung der Elektronenlawine in den Funkenkanal," Z. Phys., vol. 112, pp. 464-489, 1939.

[2] Electron Avalanches and Breakdown in Gases. London: Butterworth, 1964

[3] L. B. Loeb, "Ionizing waves of potential gradient," Sci., vol. 148, p. $1417,1965$.

[4] - Fundamental Processes of Electrical Discharges in Gases. New York: Wiley, 1939.

[5] J. M. Meek, "A theory of spark discharges," Phys. Rev., vol. 57, p. 722, 1940.

[6] G. W. Penney and G. T. Hummert, "Photoionization measurements in air, oxygen, and nitrogen," J. Appl. Phys., vol. 41, p. 572,1970 